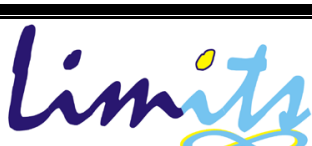

Limits: Journal of Mathematics and Its Applications

E-ISSN: 2579-8936

P-ISSN: 1829-605X

Vol. 18, No. 1, Mei 2021, 45-56

DOI: http://dx.doi.org/10.12962/limits.v18i1.6038

\title{
Implementasi Vehicle Routing Problem with Multiple Trips pada Masalah Pengangkutan Sampah
}

\author{
Maya Widyastiti ${ }^{*}$, Muhamad Awaludin ${ }^{2}$ \\ 1,2 Universitas Pakuan; Jl. Pakuan PO Box 452, Bogor 16143, Indonesia \\ ${ }^{1,2}$ Program Studi Matematika Universitas Pakuan, Bogor, Indonesia \\ e-mail: maya.widyastiti@unpak.ac.id
}

Diajukan:26 Oktober 2019, Diperbaiki: 3 Desember 2020, Diterima:31 Maret 2021

\begin{abstract}
Abstrak
Salah satu tantangan yang dihadapi oleh setiap daerah, termasuk di Kota Bogor adalah masalah pengelolaan sampah. Dari tahun ke tahun, jumlah penduduk di Kota Bogor semakin bertambah. Hal ini menyebabkan volume sampah di Kota Bogor semakin meningkat. Volume sampah di Kota Bogor setiap harinya mencapai 2900 meter kubik. Akan tetapi, sampah yang terangkut ke Tempat Pembuangan Akhir (TPA) Galuga hanya 2100 meter kubik. Hal ini dapat menyebabkan penumpukan sampah di Tempat Pembuangan Sementara (TPS). Setiap hari, Dinas Lingkungan Hidup (DLH) Kota Bogor telah melakukan pengangkutan sampah. Akan tetapi, DLH Kota Bogor memiliki keterbatasan, seperti banyaknya armada pengangkutan sampah, biaya operasional, dan sebagainya. Pada penelitian ini, model Vehicle Routing Problem with Multiple Trips diterapkan pada masalah pengangkutan sampah dengan tujuan meminimumkan biaya operasional pengangkutan sampah. Solusi diperoleh dengan bantuan perangkat lunak LINGO 11.0 menggunakan metode Branch and Bound. Hasil yang diperoleh sebesar Rp.9.469.072,22, dengan rincian Bogor Tengah sebesar Rp.941.650,205, Bogor Utara sebesar Rp.1.980.716,265, Bogor Timur sebesar Rp.1.032.562,5, Bogor Barat sebesar Rp.1.448.955,075, Bogor Selatan sebesar Rp.2.456.550, dan Tanah Sareal sebesar Rp.1.617.638,175.
\end{abstract}

Kata Kunci: Multiple trips, pengangkutan sampah, Vehicle Routing Problem

\begin{abstract}
One of the challenge that occur in every region, especially Bogor was management garbage issue. Total Bogor population has increase from year to year. That condition has increase the volume of garbage in Bogor City. Total garbage volume in Bogor city, every day was 2900 meter cubic. In the contrary, garbage volume that enter Final Landfill or we called Tempat Pembuangan Akhir (TPA) Galuga only 2100 meter cubic. Because of that, will make trash buildup in Temporary Disposal Site or we called Tempat Pembuangan Sampah Sementara (TPS). Every Day, Local Government of Enviromental Bogor or we called Dinas Lingkungan Hidup (DLH) Bogor city has transpot garbage. In the contrary. DLH Bogor City has limit in total of garbage transpot vehicle like Garbage Truck, operational cost, and many other problem. So that, this research has make a model of Vehicle Routing Problem with Multiple Trips which implement in garbage transport problem to minimize operational cost in transporting garbage. Solution to this problem has using LINGO 11.0 software with Branch and Bound method. As a result, the total operational cost was Rp.9.469.072,22, which compiled from Bogor Tengah district was Rp. 941.650,205, Bogor Utara district was Rp.1.980.716,265, Bogor Timur district was Rp 1.032.562,5, Bogor Barat district was Rp 1.448.955,075, Bogor Selatan district was Rp 2.456.550, and Tanah Sareal district was Rp 1.617.638,175.
\end{abstract}

Keywords: Garbage Transportation, Multiple Trips, Vehicle Routing Problem 


\section{Pendahuluan}

Salah satu tantangan yang dihadapi oleh setiap daerah, termasuk di Kota Bogor adalah masalah persampahan. Dari tahun ke tahun, jumlah penduduk di Kota Bogor semakin bertambah. Hal ini menyebabkan volume sampah di Kota Bogor semakin meningkat. Setiap tahunnya peningkatan volume sampah di Kota Bogor mencapai 2 persen [1]. Volume sampah di Kota Bogor setiap harinya tercatat mencapai 2900 meter kubik. Akan tetapi, sampah yang terangkut ke Tempat Pembuangan Akhir (TPA) Galuga hanya 2100 meter kubik. Selain itu, menurut catatan sanitasi Kota Bogor, laju timbunan sampah domestik atau sampah pemukiman mencapai 0,3 kg/orang/hari. Hal ini dapat menyebabkan penumpukan sampah di Tempat Pembuangan Sementara (TPS). Saat ini, DLH Kota Bogor memiliki target agar semua sampah dapat terangkut dari TPS ke TPA Galuga. Oleh karena itu, diperlukan suatu upaya untuk mengatasi masalah persampahan sehingga tidak ada lagi timbunan sampah di Kota Bogor.

Dalam pelaksanaannya, pengangkutan sampah di Kota Bogor telah dilaksanakan secara rutin setiap hari. Untuk setiap harinya, armada pengangkut sampah melakukan perjalanan sebanyak dua kali. Walau demikian, DLH Kota Bogor masih mengalami kesulitan untuk mencapai target yang diharapkan. Hal ini dikarenakan DLH Kota Bogor memiliki keterbatasan armada pengangkut sampah, biaya operasional, waktu pengangkutan sampah, dan sebagainya.

Masalah pengangkutan sampah di Kota Bogor sudah pernah dilakukan sebelumnya menggunakan Sistem Informasi Geografis [2]. Pada penelitian tersebut diperoleh rute sebanyak 88 rute perjalanan dengan total biaya operasional sebesar Rp.11.668.000 untuk dua kali perjalanan. Pada penelitian ini, masalah pengangkutan sampah akan diformulasikan ke dalam model Vehicle Routing Problem with Multiple Trips. Hal ini dikarenakan volume sampah di TPS melebihi kapasitas angkut dari armada sehingga TPS harus dikunjungi oleh lebih dari satu armada. Model yang dibentuk ini diharapkan dapat menjadi bahan pertimbangan dalam menentukan rute perjalanan armada pengangkut sampah sehingga biaya operasional dapat seminimum mungkin dan semua sampah dapat terangkut dengan baik.

Vehicle Routing Problem (VRP) merupakan masalah penentuan rute armada pengangkut dalam mengantarkan suatu barang dari produsen ke konsumen dengan tujuan meminimumkan jarak tempuh, dengan beberapa batasan antara lain setiap armada pengangkut harus memulai perjalanan dari lokasi produsen, setiap konsumen hanya akan dilayani sebanyak satu kali oleh satu armada, setiap konsumen mempunyai permintaan yang harus dipenuhi, setiap armada memiliki keterbatasan kapasitas, dan tidak terdapat subroute untuk setiap armada [3]. Saat ini, model Vehicle Routing Problem telah banyak dikembangkan menjadi beberapa variasi, antara lain Fleet Size and Mix Vehicle Routing Problem with Time Windows [4], Capacitated Vehicle Routing 
Problem [5], Vehicle Routing Problem with Deliveries and Pickup [6], Open Vehicle Routing Problem [7], multiple-trip Vehicle Routing Problem [8], dan sebagainya. Oleh karena itu, pada penelitian ini akan diimplementasikan model Vehicle Routing Problem with Multiple Trips pada pengangkutan sampah di Kota Bogor dengan tujuan meminimumkan biaya operasional yang harus dikeluarkan DLH Kota Bogor.

\section{Metode Penelitian}

Penelitian ini diawali dengan pengumpulan data-data yang diperlukan, perumusan formulasi masalah matematika, dan dilanjutkan dengan penentuan solusi dengan bantuan perangkat lunak LINGO 11.0 menggunakan metode branch and Bound.

\subsection{Data}

Pada penelitian ini, data yang dibutuhkan antara lain data banyaknya TPS di setiap kecamatan di Kota Bogor dan banyaknya armada pengangkutan sampah dengan tipe arm roll truck berkapasitas 6 ton. Data tersebut diperoleh dari Dinas Lingkungan Hidup Kota Bogor. Data TPS yang telah diperoleh kemudian dicari lokasinya dan kemudian dicari jarak antara TPA dan setiap TPS. Data jarak dari TPA ke antar TPS diperoleh dengan menggunakan bantuan google maps. Selain itu, data jumlah penduduk di Kota Bogor diperoleh dari Badan Pusat Statistik Kota Bogor. Data volume sampah di setiap kecamatan diambil berdasarkan data jumlah penduduk yang dikalikan dengan 0,3. Hal ini dikarenakan laju timbunan sampah di Bogor adalah 0,3 $\mathrm{kg} /$ orang/hari. Kemudian volume sampah tersebut dibagi sesuai dengan proporsi TPS di masingmasing kelurahan di setiap kecamatan tersebut. Banyaknya TPS yang ada di setiap kecamatan di Kota Bogor diberikan pada Tabel 1.

Tabel 1. Banyaknya TPS di setiap kecamatan

\begin{tabular}{cc}
\hline Kecamatan & $\begin{array}{c}\text { Banyaknya } \\
\text { TPS }\end{array}$ \\
\hline Bogor Tengah & 17 \\
Bogor Utara & 13 \\
Bogor Timur & 14 \\
Bogor Barat & 12 \\
Bogor Selatan & 16 \\
Tanah Sareal & 17 \\
\hline
\end{tabular}

\subsection{Formulasi Matematika}

Model Vehicle Routing Problem with Multiple Trips dapat diformulasikan sebagai berikut. 


\subsubsection{Himpunan dan Indeks}

Himpunan dan indeks yang digunakan adalah sebagai berikut.

$K=\{1,2, \ldots, r\} \quad=$ himpunan armada, dengan indeks $k$

$A=\{1,2,3, \ldots, n\}=$ himpunan TPA dan TPS, dengan indeks $i, j, l$, dimana TPA dinyatakan dengan indeks 1 .

\subsubsection{Parameter}

Parameter yang digunakan adalah sebagai berikut.

$a_{k}=$ kapasitas angkut maksimal dari armada ke- $k$

$v_{i} \quad=$ banyaknya volume sampah yang ada di TPS- $i$

$q_{i 1}=$ banyaknya volume sampah yang diangkut di TPS- $i$ pada proses pengangkutan pertama

$q_{i 2}=$ banyaknya volume sampah yang diangkut di TPS- $i$ pada proses pengangkutan kedua

$q_{i 3}=$ banyaknya volume sampah yang diangkut di TPS- $i$ pada proses pengangkutan ketiga

$d_{i j}=$ jarak dari TPS $i$ ke TPS $j$

$M \quad=$ konstanta positif yang bernilai relatif besar

$u_{k i}=$ artificial variable yang memastikan agar tidak terjadi subroute

$N \quad$ = banyaknya armada yang tersedia

\subsubsection{Variabel keputusan}

Variabel keputusan yang digunakan adalah sebagai berikut.

$$
x_{k i j}=\left\{\begin{array}{lc}
1, & \text { jika armada } k \text { mengunjungi TPS } i \text { sebelum ke TPS } j \\
0, & \text { jika selainnya }
\end{array}\right.
$$

\subsubsection{Fungsi Tujuan}

Fungsi tujuan pada masalah pengangkutan sampah adalah meminimumkan biaya, pehitungan dimulai dengan menghitung jarak tempuh armada yang kemudian dikalikan 0,53 dan Rp.5150. Formulasi fungsi tujuan dapat ditulis sebagai berikut.

$$
\text { Minimumkan }\left(\sum_{i \in A S} \sum_{j \in A S} \sum_{k \in T} d_{i j} x_{k i j}\right) \times 0.53 \times 5150
$$

\subsubsection{Kendala}

Kendala yang dibutuhkan adalah sebagai berikut.

1. Penentuan volume sampah yang diangkut

a. Jika volume sampah yang ada di setiap TPS kurang dari 6 ton, maka

$$
q_{i 1}=v_{i}
$$


b. Jika volume sampah yang ada di setiap TPS antara $6-12$ ton, maka

$$
\begin{gathered}
q_{i 2}=v_{i}-6 \\
q_{i 1}=6
\end{gathered}
$$

c. Jika volume sampah yang ada di setiap TPS melebihi 12 ton, maka

$$
\begin{gathered}
q_{i 3}=v_{i}-12 \\
q_{i 2}=6 \\
q_{i 1}=6
\end{gathered}
$$

2. Setiap armada yang akan digunakan harus keluar dari TPA,

$$
\begin{gathered}
\sum_{j \in A S} x_{k 1 j}=1, \forall k \in T \\
x_{k i j} \leq z_{k}, \forall k \in T, \forall i, j \in A S, i \neq j
\end{gathered}
$$

3. Setiap TPS diperbolehkan untuk dikunjungi lebih dari satu kali oleh satu armada

$$
\begin{aligned}
& \sum_{k \in T} \sum_{\substack{i \in N \\
i \neq j}} x_{k i j} \geq 1, \forall j \in A S \\
& \sum_{k \in T} \sum_{\substack{j \in A S \\
i \neq j}} x_{k i j} \geq 1, \forall i \in A S
\end{aligned}
$$

4. Setiap armada harus meninggalkan suatu TPS untuk mengunjungi TPS lainnya

$$
\sum_{\substack{i \in A S \\ i \neq l}} x_{k i l}-\sum_{\substack{j \in A S \\ j \neq l}} x_{k l j}=0, \forall l \in A S, \forall k \in T
$$

5. Banyaknya sampah yang diangkut sampah tidak boleh melebihi kapasitas angkut dari armada tersebut.

a. Jika volume sampah yang ada di setiap TPS kurang dari 6 ton, maka

$$
\sum_{i \in A S} \sum_{\substack{j \in A S \\ i \neq j}} q_{i 1} x_{k i j} \leq a_{k}, \forall k \in T
$$

b. Jika volume sampah yang ada di setiap TPS antara 6-12 ton, maka

$$
\sum_{i \in A S} \sum_{\substack{j \in A S \\ i \neq j}} q_{i 2} x_{k i j} \leq a_{k}, \forall k \in T
$$

c. Jika volume sampah yang ada di setiap TPS melebihi 12 ton, maka

$$
\sum_{i \in A S} \sum_{\substack{j \in A S \\ i \neq j}} q_{i 3} x_{k i j} \leq a_{k}, \forall k \in T
$$


6. Setiap armada tidak mengalami subroute

$$
u_{k i}-u_{k j}+N x_{k i j} \leq N-1, \forall k \in T, \forall i, j \in S, i \neq j
$$

\section{Hasil dan Pembahasan}

Berdasarkan formulasi matematika yang telah dibentuk, kemudian mencari solusi dengan bantuan perangkat lunak LINGO 11.0. Pada proses ini memerlukan waktu eksekusi yang cukup lama. Dari enam kecamatan, tiga kecamatan memperoleh solusi optimal, sedangkan tiga kecamatan lainnya dilakukan interupsi program setelah menjalani proses running selama lebih dari 48 jam. Kecamatan yang memperoleh solusi optimal adalah kecamatan Bogor Utara, Kecamatan Bogor Barat, dan Kecamatan Selatan, sedangkan Kecamatan Bogor Timur, Kecamatan Bogor Tengah, dan kecamatan Tanah Sareal hanya mendapatkan solusi feasible.

Berdasarkan model Vehicle Routing Problem with Multiple Trips diperoleh rute sebanyak 69 rute dengan total biaya operasional sebesar Rp.9.469.072,22 atau menempuh jarak sekitar $3469,16 \mathrm{~km}$. Hasil yang diperoleh ini telah memenuhi semua batasan kendala yang dibuat dan semua sampah di TPS telah terangkut. Selain itu, model ini juga memperoleh hasil yang lebih baik jika dibandingkan dengan penelitian yang telah dilakukan sebelumnya yang menghasilkan rute sebanyak 88 rute dan agar semua sampah dapat terangkut dilakukan dua kali perjalanan dengan biaya operasional untuk dua kali perjalanan sebesar Rp. 11.668.000 [2]. Hasil pengangkutan sampah di Kota Bogor dengan model Vehicle Routing Problem with Multiple Trips dapat dilihat pada Tabel 2. Berdasarkan Tabel 2 tersebut, dapat dilihat bahwa di Kecamatan Bogor Selatan menghasilkan rute pengangkutan terbanyak yaitu sebesar 16 rute, sedangkan kecamatan Bogor Timur menghasilkan rute pengangkutan terkecil yaitu sebesar 6 rute. Jarak tempuh terjauh terdapat di Kecamatan Bogor Selatan, sedangkan jarak tempuh terpendek terdapat di kecamatan Bogor Tengah. Semakin jauh jarak tempuh yang diperoleh menyebabkan semakin besarnya biaya operasional yang harus dikeluarkan oleh DLH Kota Bogor. Rute pengangkutan sampah di setiap kecamatan di Kota Bogor dapat dilihat pada Tabel 3 hingga Tabel 8. 
Tabel 2. Hasil Pengangkutan Sampah di Kota Bogor

\begin{tabular}{cccc}
\hline Kecamatan & Banyaknya Rute & Jarak Tempuh (km) & Biaya (Rp) \\
\hline Bogor Tengah & 7 & 344,99 & $941.650,205$ \\
Bogor Utara & 13 & 725,67 & $1.980 .716,265$ \\
Bogor Timur & 6 & 375 & $1.023 .562,5$ \\
Bogor Barat & 14 & 530,85 & $1.448 .955,075$ \\
Bogor Selatan & 16 & 900 & 2.456 .550 \\
Tanah Sareal & 13 & 592,65 & $1.617 .638,175$ \\
Total & $\mathbf{6 9}$ & $\mathbf{3 4 6 9 , 1 6}$ & $\mathbf{9 . 4 6 9 . 0 7 2 , 2 2}$ \\
\hline
\end{tabular}

Rute pengangkutan sampah di Kecamatan Bogor Tengah dapat dilihat pada Tabel 3. Pada Tabel tersebut dapat dilihat bahwa di Kecamatan Bogor Tengah terdapat 7 rute pengangkutan dengan total jarak tepuh sebesar 344,99 km sehingga besarnya biaya operasional pengangkutan sampah di Kecamatan Bogor Tengah adalah Rp.941.650,205. Total sampah yang diangkut dari setiap rute pun tidak melebihi 6 ton. Hal ini mengartikan bahwa armada armada yang mengangkut sampah di Kecamatan Bogor Tengah tidak melebihi kapasitas angkut dari armada tersebut.

Tabel 3. Rute Pengangkutan Sampah Kecamatan Bogor Tengah

\begin{tabular}{clcc}
\hline Rute ke- & \multicolumn{1}{c}{ Rute } & $\begin{array}{c}\text { Jarak } \\
(\mathbf{k m})\end{array}$ & $\begin{array}{c}\text { Volume Sampah } \\
\text { yang Diangkut (Ton) }\end{array}$ \\
\hline 1 & TPA-Pusdiksi-Sempur-TPA & 50 & 5,864 \\
2 & TPA-IPB Tegallega-Jalan Roda-TPA & 52,6 & 5,864 \\
3 & TPA-RS. PMI-Bogor Plaza-TPA & 50 & 5,864 \\
4 & TPA-Unpak-Cilibende-TPA & 54 & 5,864 \\
5 & TPA-Jalan Salmun-Sekolah Regina Pacis-SMPN 7 (Paledang)- & 48,7 & 48,7 \\
& Superindo-TPA & & \\
6 & TPA-Kantor Batu-Gedong Sawah-Propindo-Mayor Oking-TPA & 47,69 & 47,69 \\
7 & TPA-Depris-TPA & 42 & 43,98 \\
\hline
\end{tabular}

Rute Pengangkutan Sampah di Kecamatan Bogor Utara dapat dilihat pada Tabel 4. Pada Tabel 4 diperoleh 13 rute pengangkutan sampah dengan total jarak tempuh sebesar 725,67 km atau biaya operasional yang harus dikeluarkan oleh DLH Kota Bogor sebesar Rp.1.980.716,265. Kapasitas pengangkutan armada untuk rute ke-satu hingga ke-enam kurang dari 6 ton, sedangkan untuk rute ke-tujuh hingga ke-tiga belas sebesar 6 ton. Oleh karena itu, dapat disimpulkan bahwa di Kecamatan Bogor Utara, armada pengangkut sampah tidak mengangkut sampah melebihi dari kapasitas armada tersebut. 
Tabel 4. Rute Pengangkutan Sampah Kecamatan Bogor Utara

\begin{tabular}{clcc}
\hline Rute ke- & \multicolumn{1}{c}{ Rute } & $\begin{array}{c}\text { Jarak } \\
(\mathbf{k m})\end{array}$ & $\begin{array}{c}\text { Volume Sampah } \\
\text { yang Diangkut (Ton) }\end{array}$ \\
\hline 1 & TPA-Bantar Jati Atas-RS Azra-TPA & 48,17 & 5,06 \\
2 & TPA-Plaza Jambu Dua-Perum Pabaton Indah-TPA & 50,7 & 5,06 \\
3 & TPA-Ciparigi I-Brimob-Ciparigi II-TPA & 53,7 & 5,198 \\
4 & TPA-Pasar Tanah Baru-Indraprasta-TPA & 52,7 & 4,544 \\
5 & TPA-RS. Mulia-TPA & 48 & 2,53 \\
6 & TPA-Botanica-IPB III-Pandu Raya-TPA & 60,4 & 5,526 \\
7 & TPA-Indraprasta-TPA & 48 & 6 \\
8 & TPA-Ciparigi I-TPA & 50 & 6 \\
9 & TPA-Ciparigi I-TPA & 50 & 6 \\
10 & TPA-Pandu Raya-TPA & 52 & 6 \\
11 & TPA-Pandu Raya-TPA & 52 & 6 \\
12 & TPA-Botanica-TPA & 56 & 6 \\
13 & TPA-Botanica-TPA & 56 & 6 \\
\hline
\end{tabular}

Rute Pengangkutan Sampah di Kecamatan Bogor Timur dapat dilihat pada Tabel 5. Di kecamatan Bogor Timur, rute pengangkutan sampah yang diperoleh sebanyak 6 rute dengan rincian rute ke-satu hingga ke-lima volume sampah yang diangkut sebesar kurang dari 6 ton, sedangkan untuk rute ke-enam armada pengangkut sampah mampu mengangkut seberat 6 ton. Di kecamatan ini, semua kendala yang telah dibuat dengan model Vehicle Routing Problem with Multiple Trips dapat terpenuhi. Total jarak yang ditempuh oleh armada sebesar $375 \mathrm{~km}$ sehingga biaya operasional dalam proses pengangkutan sampah yang harus dikeluarkan oleh DLH Kota Bogor sebesar Rp.1.032.562,5.

Tabel 5. Rute Pengangkutan Sampah Kecamatan Bogor Timur

\begin{tabular}{clcc}
\hline Rute ke- & \multicolumn{1}{c}{ Rute } & $\begin{array}{c}\text { Jarak } \\
(\mathbf{k m})\end{array}$ & $\begin{array}{c}\text { Volume Sampah } \\
\text { yang Diangkut (Ton) }\end{array}$ \\
\hline 1 & TPA-Sukamulya-Terminal Baranang Siang-Perum. Riau-TPA & 61,8 & 5,702 \\
2 & TPA-Taman Pajajaran II-Parung Banteng-PDAM-TPA & 60,7 & 5,702 \\
3 & TPA-MBR-SKI-BMC -TPA & 70 & 5,704 \\
4 & TPA-Lorena-Binamarga-X One Sukasari-TPA & 63,9 & 5,406 \\
5 & TPA-Bakongsi-Taman Pajajaran-TPA & 66,6 & 5,704 \\
6 & TPA-X One Sukasari-TPA & 52 & 6 \\
\hline
\end{tabular}


Tabel 6. Rute Pengangkutan Sampah Kecamatan Bogor Barat

\begin{tabular}{clcc}
\hline Rute ke- & \multicolumn{1}{c}{ Rute } & $\begin{array}{c}\text { Jarak } \\
\text { (km) }\end{array}$ & $\begin{array}{c}\text { Volume Sampah } \\
\text { yang Diangkut (Ton) }\end{array}$ \\
\hline 1 & TPA-Terminal Bubulak-TPA & 32 & 4,938 \\
2 & TPA-Gang Bengkong-TPA & 38 & 5,468 \\
3 & TPA-Pasir Kuda-TPA & 44 & 4,938 \\
4 & TPA-RS. Marzuki Mahdi-Jalan Manunggal-TPA & 41,85 & 5,468 \\
5 & TPA-Yasmin Sektor 6-TPA & 36 & 5,468 \\
6 & TPA-Kapuk Loji-TPA & 38 & 4,938 \\
7 & TPA-Pusdik Intel-Gang Kelor-TPA & 39 & 5,468 \\
8 & TPA-Curug Induk-TPA & 36 & 4,938 \\
9 & TPA- Pasar Gunung Batu-TPA & 40 & 5,468 \\
10 & TPA-Giant Yasmin-TPA & 36 & 5,468 \\
11 & TPA-Terminal Bubulak-TPA & 32 & 6 \\
12 & TPA-Pasir Kuda-TPA & 44 & 6 \\
13 & TPA-Kapuk Loji-TPA & 38 & 6 \\
14 & TPA-Curug Induk-TPA & 36 & 6 \\
\hline
\end{tabular}

Rute Pengangkutan Sampah di Kecamatan Bogor Barat dapat dilihat pada Tabel 6. Pada Tabel 6 tersebut dapat dilihat bahwa jarak tempuh yang diperoleh sebesar 530,85 km dengan rute sebanyak 14 rute. Dari keempatbelas rute tersebut dapat dilihat bahwa 4 rute mampu mengangkut sampah sebesar 6 ton, sedangkan 10 rute lainnya dapat mengangkut sampah kurang dari 6 ton. Biaya operasional yang dikeluarkan untuk proses pengangkutan sampah sebesar Rp.1.448.955,075. Berdasarkan rute yang dihasilkan tersebut, tidak terdapat kendala yang dilanggar.

Tabel 7. Rute Pengangkutan Sampah Kecamatan Bogor Selatan

\begin{tabular}{clcc}
\hline Rute ke- & \multicolumn{1}{c}{ Rute } & $\begin{array}{c}\text { Jarak } \\
(\mathbf{k m})\end{array}$ & $\begin{array}{c}\text { Volume Sampah } \\
\text { yang Diangkut (Ton) }\end{array}$ \\
\hline 1 & TPA-Nutrifood-TPA & 62 & 3,218 \\
2 & TPA-Warung Bandrek-Perum Pakuan-TPA & 56,3 & 5,632 \\
3 & TPA-Pamoyanan Sari-TPA & 56 & 3,653 \\
4 & TPA-Dekeng-TPA & 60 & 3,653 \\
5 & TPA-Perumda-Bondongan -TPA & 57,2 & 5,632 \\
6 & TPA-BNR-TPA & 54 & 3,653 \\
7 & TPA-Rolita-RS Melania-TPA & 70,6 & 5,632 \\
8 & TPA-Villa Kebun Raya -TPA & 44 & 3,218 \\
9 & TPA- Jalan Pahlawan-TPA & 48 & 3,653 \\
10 & TPA-Warban-Ciawi-TPA & 63,9 & 5,632 \\
11 & TPA-Batutulis -TPA & 56 & 6 \\
\hline
\end{tabular}




\begin{tabular}{clccc}
\hline Rute ke- & Rute & $\begin{array}{c}\text { Jarak } \\
\text { (km) }\end{array}$ & $\begin{array}{c}\text { Volume Sampah } \\
\text { yang Diangkut (Ton) }\end{array}$ \\
\hline 12 & TPA-Paspampres-TPA & 54 & 6 \\
13 & TPA-Pamoyanan Sari-TPA & 56 & 6 \\
14 & TPA-Dekeng-TPA & 60 & 6 \\
15 & TPA-BNR-TPA & 54 & 6 \\
16 & TPA-Jalan Pahlawan -TPA & 48 & 6 \\
\hline
\end{tabular}

Rute Pengangkutan Sampah di Kecamatan Bogor Selatan dapat dilihat pada Tabel 7. Pada Tabel 7 dapat dilihat bahwa di kecamatan Bogor Selatan terdapat 16 rute pengangkutan sampah dengan total jarak tempuh sebesar $900 \mathrm{~km}$ atau sekitar Rp.2.456.550. Dari rute tersebut, rute kesatu hingga rute ke-sepuluh, armada pengangkut sampah mengangkut sampah dari TPS kurang dari 6 ton per harinya, sedangkan untuk rute ke-sebelas hingga ke-enambelas mampu mengangkut sampah sebesar 6 ton setiap hari.

Tabel 8. Rute Pengangkutan Sampah Kecamatan Tanah Sareal

\begin{tabular}{clcc}
\hline Rute ke- & \multicolumn{1}{c}{ Rute } & $\begin{array}{c}\text { Jarak } \\
(\mathbf{k m})\end{array}$ & $\begin{array}{c}\text { Volume Sampah } \\
\text { yang Diangkut (Ton) }\end{array}$ \\
\hline 1 & TPA-Pondok Rumput-Blender-TPA & 32 & 5,304 \\
2 & TPA-Bukit Cimanggu I-Bukit Cimanggu II-TPA & 38 & 4,244 \\
3 & TPA-Taman Sari Persada-SMPN 16-TPA & 44 & 4,244 \\
4 & TPA-Good Year-Haur Jaya -TPA & 41,85 & 5,304 \\
5 & TPA-Kedung Badak II-Kedung Badak I-TPA & 36 & 4,244 \\
6 & TPA-Lotte Mart-Yogya Plaza-TPA & 38 & 4,244 \\
7 & TPA-Kedung Badak III-Saung Kuring-TPA & 39 & 4,244 \\
8 & TPA-Sukaresmi-TPA & 36 & 6 \\
9 & TPA-Sukaresmi-TPA & 40 & 4,61 \\
10 & TPA-Pasar Jambu Dua-TPA & 36 & 6 \\
11 & TPA- Pasar Jambu Dua-TPA & 32 & 4,61 \\
12 & TPA-Sinbad Agung-TPA & 44 & 6 \\
13 & TPA-Sinbad Agung-TPA & 38 & 4,61 \\
\hline
\end{tabular}

Rute Pengangkutan Sampah di Kecamatan Tanah Sareal dapat dilihat pada Tabel 8. Di kecamatan Tanah Sareal, banyaknya rute yang dihasilkan adalah 13 rute dengan biaya operasional pengangkutan sampah sebesar Rp.1.617.638,175 atau jarak tempuh sekitar 592,65 km. Dari rute tersebut diperoleh 3 rute yang mengangkut sampah sebesar 6 ton dan 10 rute mengangkut sampah sebesar kurang dari 6 ton. Di kecamatan ini, semua kendala model Vehicle Routing Problem with Multiple Trips dapat terpenuhi. 


\section{Simpulan}

Berdasarkan penelitian di atas, dapat disimpulkan bahwa masalah pengangkutan sampah di Kota Bogor dapat dimodelkan ke dalam bentuk Vehicle Routing Problem with Multiple Trips dengan tujuan meminimumkan biaya operasional. Rute yang diperoleh menghasilkan biaya operasional yang lebih kecil apabila dibandingkan dengan penelitian yang telah dilakukan sebelumnya. Biaya operasional yang diperoleh sebesar Rp.9.478.072,22, dengan rincian:
a. Bogor Tengah sebesar Rp. 941.650,205
b. Bogor Utara sebesar Rp. 1.980.716,265
c. Bogor Timur sebesar Rp. 1.032.562,5
d. Bogor Barat sebesar Rp. 1.448.955,075
e. Bogor Selatan sebesar Rp. 2.456.550
f. Tanah Sareal sebesar Rp. 1.617.638,175

\section{Ucapan Terima Kasih}

Ucapan terima kasih ini kami tujukan kepada Universitas Pakuan, Dinas Lingkungan Hidup Kota Bogor, dan semua pihak terkait sehingga penelitian ini dapat terlaksana dengan baik.

\section{Daftar Pustaka}

[1] Nugroho, L. A. 2018. Volume Sampah Kota Bogor Naik 2 Persen, Kebanyakan dari Rumah Tangga. (Online). (http://bogor.tribunnews.com/2018/04/10/volume-sampah-kota-bogornaik-2-persen-kebanyakan-dari-rumah-tangga, diakses 4 April 2019).

[2] Apriyanti, D., Kresnawati, D. K. \& Diniyah, W. F. (2018). Pemanfaatan Sistem Informasi Geografis Untuk Analisis Rute Armada Pengangkutan Sampah Di Kota Bogor. Proceeding National Seminar of Geomatics Geospatial Information Agency. Bogor, Indonesia.

[3] Toth P, Vigo D. (2002). An overview of vehicle routing problems. Di dalam Toth P, et al., editor. The Vehicle Routing Problem. Philadelphia: Siam; hlm. 1-26.

[4] Hiermann, G., Puchinger, J., Ropke, S., Harlt, R. F. (2016). The Electric Fleet Size and Mix Vehicle Routing Problem with Time Windows and Researching Stations. European Journal of Operational Research 252(2),995-1018.

[5] Baran, E. (2018). Route Determination for Capacitated Vehicle Routing Problem with Two Different Hybrid Heuristic Algorithm. International Journal of Engineering Science and Application 2(2). 
[6] Wassan, N. A. \& Nagy Gabor. (2014). Vehicle Routing Problem with Deliveries and Pickups: Modelling Issues and Meta-heuristics Solution Approaches. International Journal of Transportation 2(1),95-110.

[7] Grangier, P., Gendreau, M., Lehuede, F. \& Rousseau, L. M. (2016). An Adaptive Large Neighborhood Search For The Two-Echelon Multiple-Trip Vehicle Routing Problem With Satellite Synchronization. European journal of operational research 254(1), 80-91.

[8] Vincent, F. Y., Jewpanya P. \& Redi, A. A. N. P. (2016). Open Vehicle Routing Problem With Cross-Docking. Computers \& Industrial Engineering 94, 6-17. 